\title{
Comparison of the effects of sevoflurane and propofol anesthesia on pulmonary function, MMP-9 and postoperative cognition in patients receiving lung cancer resection
}

\author{
GUAN WANG $^{1 *}, \mathrm{JIE} \mathrm{LIU}^{1 *}, \mathrm{JINXIA} \mathrm{GAO}^{1}$ and XIN ZHENG ${ }^{2}$ \\ Departments of ${ }^{1}$ Anesthesiology and ${ }^{2}$ Emergency Anesthesiology, \\ The Second Hospital of Dalian Medical University, Dalian, Liaoning 116023, P.R. China
}

Received August 16, 2018; Accepted January 7, 2019

DOI: $10.3892 / \mathrm{ol} .2019 .9993$

\begin{abstract}
Effects of sevoflurane and propofol anesthesia on pulmonary function, matrix metalloproteinase-9 (MMP-9) and postoperative cognition were compared in patients undergoing simple resection of lower lobe of left lung. Retrospective method was used to analyze 58 cases of lung cancer patients treated by simple resection of lower lobe of left lung in the Second Hospital of Dalian Medical University from October 2016 to October 2017, and they were divided into two groups: Sevoflurane group $(n=32)$ with sevoflurane anesthesia and propofol group $(n=26)$ with propofol anesthesia. In the present study, the moment before induction of anesthesia (T1), before the start of one-lung ventilation (T2), before the end of one-lung ventilation (T3), after closed chest surgery (T4), $24 \mathrm{~h}$ after surgery (T5), calculate alveolar-arterial oxygen difference (A-aDO2), respiratory index (RI) and intrapulmonary shunt ratio $(\mathrm{Qs} / \mathrm{Qt})$, were compared between the two groups. The serum MMP-9 concentration at T1, T4 and T5 were detected by enzyme linked immunosorbent assay. The cognitive function of two groups was assessed by Mini-Mental State Examination (MMSE) 1 day before surgery and 1 and 10 days after surgery. The A-aDO2 level at T4 in sevoflurane group was significantly higher than that in propofol group $(\mathrm{P}<0.05)$. The RI level at T3, T4, the Qs/Qt and the MMP-9 level at T4
\end{abstract}

Correspondence to: Dr Jinxia Gao, Department of Anesthesiology, The Second Hospital of Dalian Medical University, 467 Zhongshan Road, Dalian, Liaoning 116023, P.R. China

E-mail: gqp7et@163.com

Dr Xin Zheng, Department of Emergency Anesthesiology, The Second Hospital of Dalian Medical University, 467 Zhongshan Road, Dalian, Liaoning 116023, P.R. China

E-mail: zhengxinxin008@163.com

*Contributed equally

Key words: sevoflurane, propofol, lung cancer resection, pulmonary function, MMP-9, cognitive function in the sevoflurane group was significantly higher than that in the propofol group $(\mathrm{P}<0.05)$. The MMSE score in sevoflurane group was significantly lower than that in propofol group 1 and 10 days after surgery $(\mathrm{P}<0.05)$. Propofol has little effect on pulmonary function and can decrease inflammatory factor MMP-9. Both sevoflurane and propofol have an effect on cognitive function after lung cancer resection, but propofol can reduce cognitive impairment in patients with lung cancer.

\section{Introduction}

Lung cancer has the highest morbidity and mortality rate in the male population and the second highest in the female population among the common malignant tumors in the world (1). There are about 1.8 million new cases of lung cancer and 1.6 million deaths in the world every year, and the 5-year survival rate is only $15 \%(2,3)$. The risk factors for lung cancer include industrial pollution, air pollution, genetic factors, and smoking (4).

Lung cancer resection is one of the most important methods in the treatment of early lung cancer in clinic. However, postoperative cognitive impairment is a problem that clinicians have always been trying to overcome. It has been proved that anesthesia can cause brain cognitive impairment, which can increase the recovery time and financial burden in mild cases and become life-threatening in severe cases $(5,6)$. At the same time, it is easy to cause a certain degree of lung ischemia-reperfusion injury and affect the pulmonary function, thus affecting the prognosis of patients because of the need of resection of partial lung tissue after surgery (7). Serum matrix metalloproteinase-9 (MMP-9) is one of the proteolytic enzymes released by neutrophils. The release of MMP-9 by neutrophils is considered to play an important role in promoting pulmonary inflammation by degrading basement membrane and migrating neutrophils to lung tissues and airways (8). According to reports in the literature, some anaesthetics have effects of cell protection and are anti-inflammatory (9). Therefore, how to improve anesthetic methods and reduce the malignant effects of anesthesia on pulmonary function and cognitive function is a very important issue.

The purpose of this study was to compare the effects of sevoflurane and propofol anesthesia on pulmonary function, 
MMP-9 and postoperative cognition in patients undergoing simple resection of the lower lobe of left lung, and to provide a theoretical basis for better clinical choice of anaesthetics.

\section{Patients and methods}

Basic information. A total of 58 cases of lung cancer treated by simple resection of lower lobe of left lung in the Second Hospital of Dalian Medical University (Dalian, China) from October 2016 to October 2017 were analyzed retrospectively, including 36 males and 22 females with an average age of $52.68 \pm 14.52$ years. They were divided into two groups: Sevoflurane group $(n=32)$ with sevoflurane anesthesia and propofol group $(n=26)$ with propofol anesthesia. There was no significant difference in the basic information between the two groups $(\mathrm{P}>0.05)$. Pregnancy and lactation, autoimmune diseases, chronic inflammation, diabetes, hypertension and heart disease were excluded in all cases, and all patients had normal liver and kidney function and did not receive radiotherapy, chemotherapy, hormones and other drug analgesia, or anti-inflammatory treatment before surgery.

The study was approved by the Ethics Committee of the Second Hospital of Dalian Medical University. Patients who participated in this research had complete clinical data. The signed informed consents were obtained from the patients or the guardians (Table I).

Treatment methods. The patients were prohibited from eating for $8 \mathrm{~h}$ and using medication before the surgery, and $0.2 \mathrm{mg} / \mathrm{kg}$ midazolam intravenous injection (H20031037; Jiangsu Enhua Pharmaceutical Group Co., Ltd., Jiangsu, China) was conducted $30 \mathrm{~min}$ prior to surgery. Invasive monitoring of angiosthenia, central venous pressure, electrocardiogram, blood pressure, heart rate, pulse and oxygen protection was established In propofol group, propofol (H20030114; Sichuan Guorui Pharmaceutical Co., Ltd., Sichuan, China) target-controlled infusion (plasma concentration $3 \mu \mathrm{g} / \mathrm{ml}$ ), $3 \mu \mathrm{g} / \mathrm{kg}$ fentanyl (H20030197; Yichang Humanwell Pharmaceutical Co., Ltd., Yichang, China), and $0.3 \mathrm{mg} / \mathrm{kg}$ atracurium (H20060869; Jiangsu Hengrui Pharmaceutical Co., Ltd., Jiangsu, China) rapidly induced endotracheal intubation by intravenous injection. After intubation, the flow of inhaled oxygen was $2.0 \mathrm{l} / \mathrm{min}$, the tidal volume was $8-10 \mathrm{ml} / \mathrm{kg}$, the respiratory rate was $10-12$ times/min, and the respiratory ratio was $1: 1.5$. TCI pump (cp-660tci pump; Shanghai Huanxi Medical equipment Co., Ltd., Shanghai, China) propofol target controlled infusion (plasma concentration $4 \mu \mathrm{g} / \mathrm{ml}$ ) was used to maintain anesthesia. In sevoflurane group, 6\% sevoflurane (H35020148; Fujian Gutian Pharmaceutical Co., Ltd., Fujian, China) with $5 \mathrm{l} / \mathrm{min}$ oxygen flow was initially inhaled. The patients were asked to take a deep breath and applied positive pressure manual ventilation when their consciousness disappeared. The oxygen flow was reduced to $2 \mathrm{l} / \mathrm{min}$, and the concentration of sevoflurane in the volatile tank was adjusted to maintain the end-expiratory sevoflurane concentration in the gas monitor at 1.0 MAC, fentanyl $3 \mu \mathrm{g} / \mathrm{kg}$, atracurium $0.5-0.6 \mathrm{mg} / \mathrm{kg}$ rapidly induced endotracheal intubation by intravenous injection, and $3 \%$ sevoflurane was inhaled continuously for maintenance of anesthesia. Both groups received continuous infusion of atracurium and fentanyl with micro-infusion pump during surgery, and the average BIS was maintained between 40 and $60 \%$.

Observation index. The moment before induction of anesthesia (T1), before the start of one-lung ventilation (T2), before the end of one-lung ventilation (T3), after closed chest surgery (T4), $24 \mathrm{~h}$ after surgery (T5), calculate alveolar-arterial oxygen difference (A-aD02), respiratory index (RI) and intrapulmonary shunt ratio (Qs/Qt) were compared between the two groups (10).

The MMP-9 concentration in patients at T1, T4 and T5 was detected by ELISA (Shanghai Xinfan Biotechnology Co., Ltd., Shanghai, China). Then, $3 \mathrm{ml}$ peripheral venous blood was drawn from all patients at $\mathrm{T} 1, \mathrm{~T} 4$ and $\mathrm{T} 5$ and centrifuged with $3,000 \mathrm{x}$ g for $8 \mathrm{~min}$ at $4^{\circ} \mathrm{C}$. The serum was collected and the level of MMP-9 was detected by ELISA. The specific operation methods were strictly in accordance with the instructions.

The cognitive function of two groups was assessed according to Mini-Mental State Examination (MMSE) 1 day before surgery and 1 and 10 days after surgery. The total score of MMSE is 30 points, and the normal range is $27-30$ points. A decrease of 2 points is statistically significant. A total score of 23 or less can be diagnosed as POCD. In addition, the occurrence of restlessness in patients was recorded after surgery (11).

Statistical analysis. The data was analyzed by SPSS 20.0 statistical software (IBM Corp., Armonk, NY, USA). Chi-square test was used for count data. t-test was used for paired comparisons, and one-way ANOVA was used for multiple comparisons. The repetitive measure analysis of variance (ANOVA) was used in the comparison of different times within the group with Least Significant Difference test. $\mathrm{P}<0.05$ was considered to indicate a statistically significant difference.

\section{Results}

Comparison of pulmonary function between two groups. There was no significant difference in A-aDO2 level at T1, $\mathrm{T} 2, \mathrm{~T} 3, \mathrm{~T} 5$ between sevoflurane and propofol groups $(\mathrm{P}>0.05)$. The A-aDO2 level at T4 in sevoflurane group was significantly higher than that in propofol group, and the difference was statistically significant $(\mathrm{P}<0.05)$. Both sevoflurane and propofol groups had significantly higher $\mathrm{A}-\mathrm{aDO} 2$ level at $\mathrm{T} 2$, T3, T4 and T5 than that at T1. Both sevoflurane and propofol groups had significantly higher A-aDO2 level at T3 and T4 than that at T2, and both sevoflurane and propofol groups had significantly lower A-aDO2 level at T5 than that at T2. Both sevoflurane and propofol groups had significantly lower A-aDO2 level at T4 and T5 than that at T3. Both sevoflurane and propofol groups had significantly lower A-aDO2 level at T5 than that at T4, and the difference was statistically significant $(\mathrm{P}<0.05)$.

There was no significant difference in RI level at T1, T2, $\mathrm{T} 5$ between sevoflurane and propofol groups $(\mathrm{P}>0.05)$. The RI level at T3, T4 in sevoflurane group was significantly higher than that in propofol group, and the difference was statistically significant $(\mathrm{P}<0.05)$. Both sevoflurane and propofol groups had significantly higher RI level at T2, T3, T4 and T5 than that at T1. Both sevoflurane and propofol groups had 
Table I. Basic information [n (\%)].

\begin{tabular}{|c|c|c|c|c|}
\hline \multirow[b]{2}{*}{ Factors } & \multicolumn{2}{|c|}{ Groups } & \multirow[b]{2}{*}{$t / \chi^{2}$} & \multirow[b]{2}{*}{ P-value } \\
\hline & Sevoflurane $(n=32)$ & Propofol $(\mathrm{n}=26)$ & & \\
\hline Age (years) & & & 0.288 & 0.782 \\
\hline$<52$ & $12(37.50)$ & $8(30.77)$ & & \\
\hline$\geq 52$ & $20(62.50)$ & $18(69.23)$ & & \\
\hline Sex & & & 0.220 & 0.787 \\
\hline Male & $19(59.38)$ & $17(65.38)$ & & \\
\hline Female & $13(40.62)$ & $9(34.62)$ & & \\
\hline $\mathrm{BMI}\left(\mathrm{kg} / \mathrm{m}^{2}\right)$ & $26.42 \pm 1.05$ & $25.84 \pm 1.17$ & 1.988 & 0.052 \\
\hline Operation duration (min) & $194.52 \pm 42.41$ & $195.83 \pm 45.61$ & 0.113 & 0.910 \\
\hline Revival time (min) & $22.15 \pm 8.23$ & $23.36 \pm 9.42$ & 0.522 & 0.604 \\
\hline Smoking status & & & 0.620 & 0.543 \\
\hline Used to smoke & $23(71.88)$ & $21(80.77)$ & & \\
\hline Never smoke & $9(28.12)$ & $5(19.23)$ & & \\
\hline ASA classification & & & 1.115 & 0.429 \\
\hline I & $18(56.25)$ & $11(42.31)$ & & \\
\hline II & $14(43.75)$ & $15(57.69)$ & & \\
\hline Degree of education & & & 0.130 & 0.778 \\
\hline Junior secondary school and below & $10(31.25)$ & 7 (26.92) & & \\
\hline Junior high school or above & $22(68.75)$ & $19(73.08)$ & & \\
\hline Preoperative heart rate (time /min) & $78.23 \pm 9.13$ & $77.84 \pm 8.91$ & 0.164 & 0.871 \\
\hline Mean arterial pressure during operation ( $\mathrm{mmHg}$ ) & $88.62 \pm 15.22$ & $86.28 \pm 16.57$ & 0.560 & 0.578 \\
\hline Blood loss during operation (ml) & $102.56 \pm 34.85$ & $100.17 \pm 29.74$ & 0.277 & 0.783 \\
\hline Infusion volume during operation (ml) & $1,263.25 \pm 342.12$ & $1,186.64 \pm 320.73$ & 0.872 & 0.387 \\
\hline
\end{tabular}

significantly higher RI level at T3 and T4 than that at T2, and both sevoflurane and propofol groups had significantly lower RI level at T5 than that at T2. Both sevoflurane and propofol groups had significantly lower RI level at T4 and T5 than that at T3. Both sevoflurane and propofol groups had significantly lower RI level at T5 than that at T4, and the difference was statistically significant $(\mathrm{P}<0.05)$.

There was no significant difference in Qs/Qt at T1, T5 between sevoflurane and propofol groups $(\mathrm{P}>0.05)$. The $\mathrm{Qs} / \mathrm{Qt}$ at T2, T3 and T4 in sevoflurane group was significantly higher than that in propofol group, and the difference was statistically significant $(\mathrm{P}<0.05)$. Both sevoflurane and propofol groups had significantly higher Qs/Qt at T2, T3, T4 and T5 than that at T1. Both sevoflurane and propofol groups had significantly higher Qs/Qt at T3 and T4 than that at T2, and both sevoflurane and propofol groups had significantly lower Qs/Qt at T5 than that at T2. Both sevoflurane and propofol groups had significantly lower Qs/Qt at T4 and T5 than that at T3. Both sevoflurane and propofol groups had significantly lower Qs/Qt at T5 than that at T4, and the difference was statistically significant $(\mathrm{P}<0.05$; Fig. 1 and Table II).

Comparison of MMP-9 between the two groups. There was no significant difference in MMP-9 level at T1 and T5 between sevoflurane and propofol group $(\mathrm{P}>0.05)$. The MMP-9 level at T4 in the sevoflurane group was significantly higher than that in the propofol group, and the difference was statistically significant $(\mathrm{P}<0.05)$. Both sevoflurane and propofol groups had significantly higher MMP-9 level at T4 and T5 than that at T1. Both sevoflurane and propofol groups had significantly lower MMP-9 level at T5 than that at T4, and the difference was statistically significant $(\mathrm{P}<0.05$; Fig. 2 and Table III).

Comparison of cognitive function between the two groups. There was no significant difference in MMSE score between sevoflurane and propofol groups 1 day before surgery $(\mathrm{P}>0.05)$. The MMSE score in sevoflurane group was significantly lower than that in propofol group 1 and 10 days after surgery, and the difference was statistically significant $(\mathrm{P}<0.05)$. Both sevoflurane and propofol groups had significantly lower MMSE score of 1 and 10 days after surgery than that of 1 day before surgery. Both sevoflurane and propofol groups had significantly higher MMSE score of 10 days after surgery than that of 1 day after surgery, and the difference was statistically significant $(\mathrm{P}<0.05$; Fig. 3 and Table IV).

\section{Discussion}

According to literature reports, $\mathrm{A}-\mathrm{aDO} 2$ and $\mathrm{RI}$ are the main indicators of pulmonary diffusion function. There is a positive correlation between the index value and the degree of lung injury. The larger the value is, the more serious the 
Table II. Comparison of pulmonary function between two groups.

\begin{tabular}{|c|c|c|c|c|c|c|c|c|}
\hline Index & No. & $\mathrm{T} 1$ & $\mathrm{~T} 2$ & $\mathrm{~T} 3$ & $\mathrm{~T} 4$ & T5 & $\mathrm{F}$ & P-value \\
\hline \multicolumn{9}{|c|}{ A-aDO2 (mmHg) } \\
\hline Sevoflurane & 32 & $23.56 \pm 1.72$ & $213.54 \pm 28.46^{\mathrm{a}}$ & $426.52 \pm 43.26^{\mathrm{a}, \mathrm{b}}$ & $244.73 \pm 33.25^{\mathrm{a}-\mathrm{c}}$ & $26.49 \pm 1.93^{\mathrm{a}-\mathrm{d}}$ & 1201.00 & $<0.05$ \\
\hline Propofol & 26 & $23.41 \pm 1.47$ & $207.16 \pm 25.31^{\mathrm{a}}$ & $413.64 \pm 44.82^{\mathrm{a}, \mathrm{b}}$ & $219.67 \pm 31.48^{\mathrm{a}-\mathrm{c}}$ & $25.64 \pm 1.75^{\mathrm{a}-\mathrm{d}}$ & 938.10 & $<0.05$ \\
\hline $\mathrm{t}$ & & 0.352 & 0.892 & 1.110 & 2.923 & 1.738 & & \\
\hline P-value & & 0.726 & 0.376 & 0.272 & 0.005 & 0.088 & & \\
\hline \multicolumn{9}{|l|}{ RI } \\
\hline Sevoflurane & 32 & $0.26 \pm 0.02$ & $0.52 \pm 0.08^{\mathrm{a}}$ & $2.06 \pm 0.33^{\mathrm{a}, \mathrm{b}}$ & $0.82 \pm 0.13^{\mathrm{a}-\mathrm{c}}$ & $0.33 \pm 0.06^{\mathrm{a}-\mathrm{d}}$ & 639.90 & $<0.05$ \\
\hline Propofol & 26 & $0.25 \pm 0.03$ & $0.49 \pm 0.09^{\mathrm{a}}$ & $1.82 \pm 0.24^{\mathrm{a}, \mathrm{b}}$ & $0.71 \pm 0.12^{\mathrm{a}-\mathrm{c}}$ & $0.34 \pm 0.07^{\mathrm{a}-\mathrm{d}}$ & 616.10 & $<0.05$ \\
\hline $\mathrm{t}$ & & 1.517 & 1.343 & 3.100 & 3.316 & 0.586 & & \\
\hline P-value & & 0.135 & 0.185 & 0.003 & 0.002 & 0.560 & & \\
\hline \multicolumn{9}{|l|}{ Qs/Qt (\%) } \\
\hline Sevoflurane & 32 & $8.92 \pm 1.24$ & $12.68 \pm 1.72^{\mathrm{a}}$ & $24.56 \pm 3.17^{\mathrm{a}, \mathrm{b}}$ & $15.28 \pm 1.93^{\mathrm{a}-\mathrm{c}}$ & $9.43 \pm 1.92^{\mathrm{a}-\mathrm{d}}$ & 294.10 & $<0.05$ \\
\hline Propofol & 26 & $8.67 \pm 1.52$ & $10.93 \pm 1.74^{\mathrm{a}}$ & $20.73 \pm 2.73^{a, b}$ & $13.15 \pm 1.62^{\mathrm{a}-\mathrm{c}}$ & $9.34 \pm 1.75^{\mathrm{a}-\mathrm{d}}$ & 167.50 & $<0.05$ \\
\hline $\mathrm{t}$ & & 0.690 & 3.834 & 4.865 & 4.486 & 0.185 & & \\
\hline P-value & & 0.493 & $<0.05$ & $<0.05$ & $<0.05$ & 0.854 & & \\
\hline
\end{tabular}

${ }^{\mathrm{a}} \mathrm{P}<0.05$ compared with $\mathrm{T} 1 ;{ }^{\mathrm{b}} \mathrm{P}<0.05$ compared with $\mathrm{T} 2$; ${ }^{\mathrm{P}}<0.05$ compared with $\mathrm{T} 3$; ${ }^{\mathrm{d}} \mathrm{P}<0.05$ compared with $\mathrm{T} 4$. A-aDO2, alveolar-arterial oxygen difference; RI, respiratory index; Qs/Qt, intrapulmonary shunt ratio.
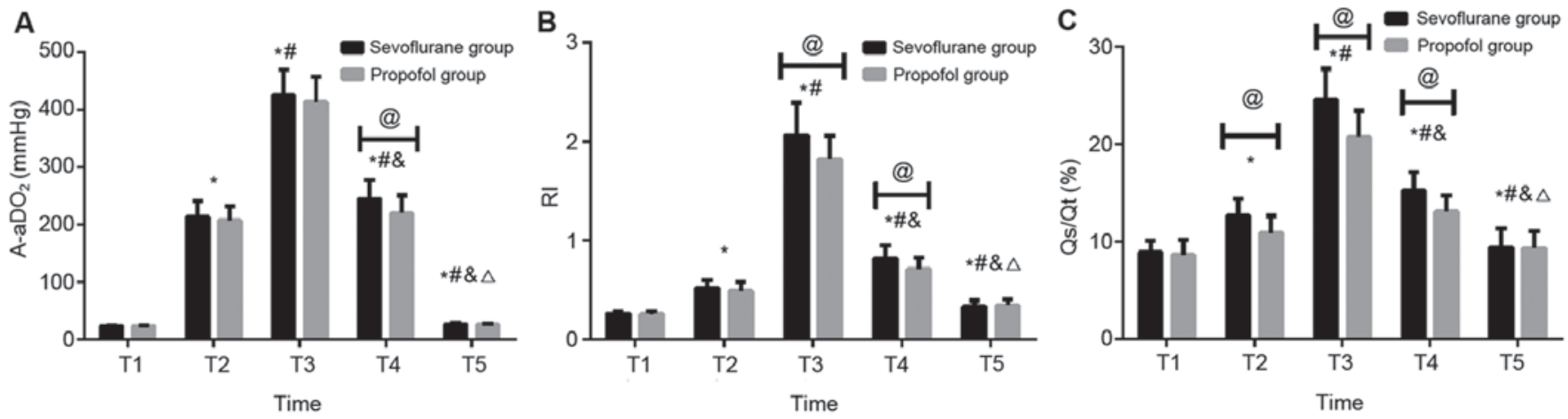

Figure 1. Comparison of pulmonary function between two groups. (A) There was no significant difference in A-aDO2 level at T1, T2, T3 and T5 between sevoflurane and propofol groups $(\mathrm{P}>0.05)$. The $\mathrm{A}-\mathrm{aDO} 2$ level at $\mathrm{T} 4 \mathrm{in}$ sevoflurane group was significantly higher than that in propofol group, and the difference was statistically significant $(\mathrm{P}<0.05)$. Both sevoflurane and propofol groups had significantly higher A-aDO2 level at T2, T3, T4 and T5 than that at T1. Both sevoflurane and propofol groups had significantly higher A-aDO2 level at T3 and T4 than that at T2, and both sevoflurane and propofol groups had significantly lower A-aDO2 level at T5 than that at T2. Both sevoflurane and propofol groups had significantly lower A-aDO2 level at T4 and T5 than that at T3. Both sevoflurane and propofol groups had significantly lower A-aDO2 level at T5 than that at $\mathrm{T} 4$, and the difference was statistically significant $(\mathrm{P}<0.05)$. (B) There was no significant difference in RI level at T1, T2 and T5 between sevoflurane and propofol groups ( $\mathrm{P}>0.05)$. The RI level at T3 and T4 in sevoflurane group was significantly higher than that in propofol group, and the difference was statistically significant $(\mathrm{P}<0.05)$. Both sevoflurane and propofol groups had significantly higher RI level at T2, T3, T4 and T5 than that at T1. Both sevoflurane and propofol groups had significantly higher RI level at T3 and T4 than that at $\mathrm{T} 2$, and both sevoflurane and propofol groups had significantly lower RI level at T5 than that at T2. Both sevoflurane and propofol groups had significantly lower RI level at T4, T5 than that at T3. Both sevoflurane and propofol groups had significantly lower RI level at T5 than that at T4, and the difference was statistically significant $(\mathrm{P}<0.05)$. (C) There was no significant difference in Qs/Qt at T1, T5 between sevoflurane and propofol group $(\mathrm{P}>0.05)$. The $\mathrm{Qs} / \mathrm{Qt}$ at $\mathrm{T} 2$, T3 and T4 in sevoflurane group was significantly higher than that in propofol group, and the difference was statistically significant $(\mathrm{P}<0.05)$. Both sevoflurane and propofol groups had significantly higher Qs/Qt at T2, T3, T4 and T5 than that at T1. Both sevoflurane and propofol groups had significantly higher Qs/Qt at T3 and T4 than that at T2, and both sevoflurane and propofol groups had significantly lower Qs/Qt at T5 than that at T2. Both sevoflurane and propofol groups had significantly lower Qs/Qt at T4 and T5 than that at T3. Both sevoflurane and propofol groups had significantly lower Qs/Qt at T5 than that at T4, and the difference was statistically significant $(\mathrm{P}<0.05)$. ${ }^{*} \mathrm{P}<0.05$ compared with $\mathrm{T} 1 ;{ }^{\text {"}} \mathrm{P}<0.05$ compared with $\mathrm{T} 2$; ${ }^{\circledR} \mathrm{P}<0.05$ compared with $\mathrm{T} 3 ;{ }^{\circ} \mathrm{P}<0.05$ compared with T4; ${ }^{\circledR} \mathrm{P}<0.05$. A-aDO2, alveolar-arterial oxygen difference; RI, respiratory index; Qs/Qt, intrapulmonary shunt ratio.

lung injury is (12). Qs/Qt is associated with planing defects, causing arterial blood flow into the pulmonary vein to cause Qs/Qt to rise (13). MMP-9 is a proteolytic enzyme that activates inflammatory mediators and cells in the lung and increases the permeability of pulmonary capillaries, which leads to pneumonedema (14). The total score of MMSE is 30 points and less than 23 points are regarded as cognitive dysfunction (15). Propofol is the most widely used intravenous anesthesia in clinical surgical treatment and has the function of antioxidation and inhibition of inflammation. It is generally 
Table III. Comparison of MMP-9 between the two groups.

\begin{tabular}{lcccrr}
\hline Index & No. & T1 & T4 & T5 & F \\
\hline MMP-9 (ng/ml) & & & & & \\
Sevoflurane & 32 & $100.26 \pm 14.85$ & $186.72 \pm 19.42^{\mathrm{a}}$ & $114.56 \pm 15.61^{\mathrm{a}, \mathrm{b}}$ & 245.100 \\
Propofol & 26 & $102.14 \pm 13.76$ & $167.25 \pm 14.73^{\mathrm{a}}$ & $109.68 \pm 15.26^{\mathrm{a}, \mathrm{b}}$ & 154.800 \\
$\mathrm{t}$ & 0.495 & 4.218 & 1.196 & $<0.05$ \\
P-value & 0.622 & $<0.05$ & 0.237 & & $<05$ \\
\hline
\end{tabular}

${ }^{\text {a }} \mathrm{P}<0.05$ compared with $\mathrm{T} 1$; ${ }^{\mathrm{b}} \mathrm{P}<0.05$ compared with T4. MMP-9, matrix metalloproteinase-9.

Table IV. Comparison of cognitive function between the two groups.

\begin{tabular}{|c|c|c|c|c|c|c|}
\hline Index & No. & 1 day before surgery & 1 day after surgery & 10 day after surgery & $\mathrm{F}$ & P-value \\
\hline \multicolumn{7}{|l|}{ MMSE score } \\
\hline Sevoflurane & 32 & $28.86 \pm 1.13$ & $21.84 \pm 1.02^{\mathrm{a}}$ & $27.21 \pm 1.03^{\mathrm{a}, \mathrm{b}}$ & 311.100 & $<0.05$ \\
\hline Propofol & 26 & $29.23 \pm 1.05$ & $24.86 \pm 1.08^{\mathrm{a}}$ & $28.65 \pm 1.18^{\mathrm{a}, \mathrm{b}}$ & 147.700 & $<0.05$ \\
\hline $\mathrm{t}$ & & 1.290 & 10.860 & 4.889 & & \\
\hline P-value & & 0.202 & $<0.05$ & $<0.05$ & & \\
\hline
\end{tabular}

${ }^{\mathrm{a}} \mathrm{P}<0.05$ compared with 1 day before surgery; ${ }^{\mathrm{b}} \mathrm{P}<0.05$ compared with 1 day after surgery. MMSE, Mini-Mental State Examination.

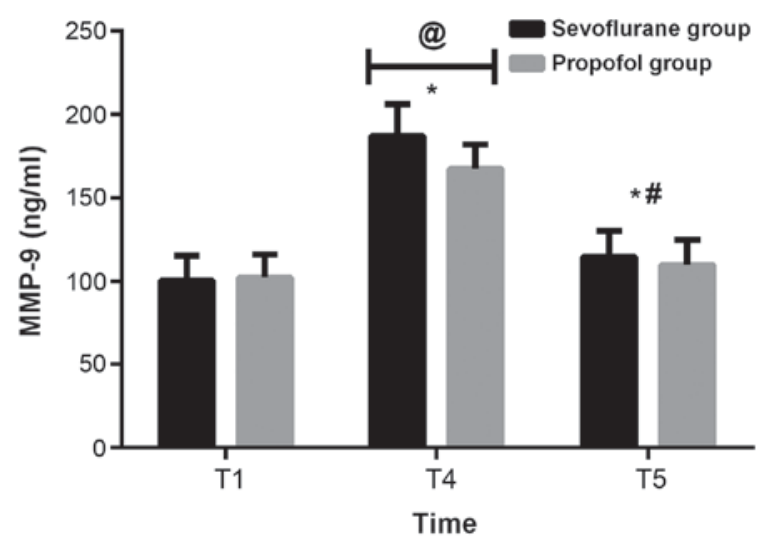

Figure 2. Comparison of MMP-9 between the two groups. There was no significant difference in MMP-9 level at T1 and T5 between sevoflurane and propofol groups $(\mathrm{P}>0.05)$. The MMP-9 level at T4 in the sevoflurane group was significantly higher than that in the propofol group, the difference was statistically significant $(\mathrm{P}<0.05)$. Both sevoflurane and propofol groups had significantly higher MMP-9 level at T4 and T5 than that at T1. Both sevoflurane and propofol groups had significantly lower MMP-9 level at T5 than that at $\mathrm{T} 4$, and the difference is statistically significant $(\mathrm{P}<0.05) .{ }^{*} \mathrm{P}<0.05$ compared with $\mathrm{T} 1 ;{ }^{\prime} \mathrm{P}<0.05$ compared with $\mathrm{T} 4 ;{ }^{\circledR} \mathrm{P}<0.05$. MMP-9; matrix metalloproteinase-9.

more stable when inducing anesthesia and rarely irritation symptoms appear (16). Sevoflurane is a new type of inhaled anesthesia with no irritation of upper respiratory tract, low inhibition of respiration, rapid recovery after surgery and short recovery time (17).

Pulmonary lobectomy often results in patients breathing only through one lobe. Currently, hypoxic pulmonary vasoconstriction of non-ventilated lung is an important factor affecting arterial partial pressure of oxygen. Therefore,

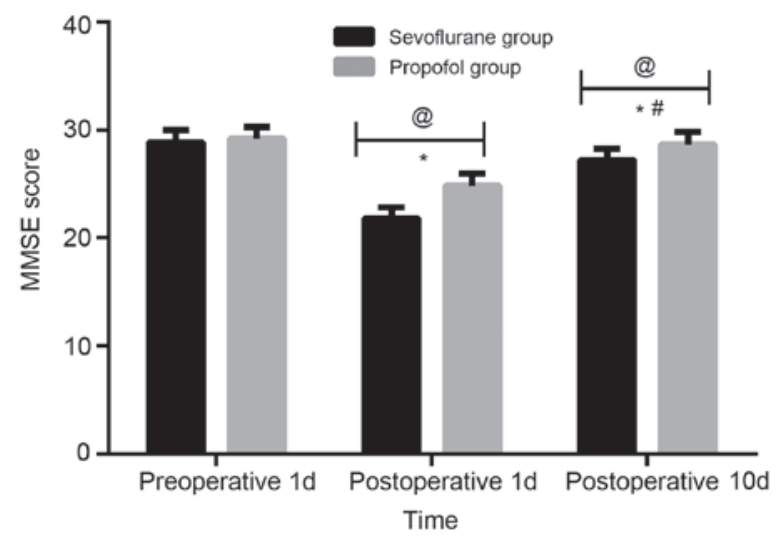

Figure 3. Comparison of cognitive function between the two groups. There was no significant difference in MMSE score between sevoflurane group and propofol group 1 day before surgery $(\mathrm{P}>0.05)$. The MMSE score in sevoflurane group was significantly lower than that in propofol group 1 and 10 days after surgery, and the difference was statistically significant $(\mathrm{P}<0.05)$. Both sevoflurane and propofol groups had significantly lower MMSE score of 1 and 10 days after surgery than that of 1 day before surgery. Both sevoflurane and propofol groups had significantly higher MMSE score of $10 \mathrm{~d}$ after surgery than that of 1 day after surgery, and the difference was statistically significant $(\mathrm{P}<0.05)$. ${ }^{*} \mathrm{P}<0.05$ compared with 1 day before surgery; ${ }^{*} \mathrm{P}<0.05$ compared with 1 day after surgery; ${ }^{\circledR} \mathrm{P}<0.05$; MMSE, Mini-Mental State Examination.

A-aDO2, RI and Qs/Qt can be used as indicators for evaluating pulmonary function of patients (18). In this study, there was no significant difference in the clinical data of patients ( $\mathrm{P}>0.05)$, thus the data was comparable. The A-aDO2 level at T4 in sevoflurane group was significantly higher than that in propofol group, the difference was statistically significant $(\mathrm{P}<0.05)$. The RI level at T3 and T4 in sevoflurane group 
was significantly higher than that in propofol group, and the difference was statistically significant $(\mathrm{P}<0.05)$. The $\mathrm{Qs} / \mathrm{Qt}$ level at T2 and T3 and T4 in sevoflurane group was significantly higher than that in propofol group, and the difference was statistically significant $(\mathrm{P}<0.05)$. The MMP-9 level at T4 in the sevoflurane group was significantly higher than that in the propofol group, and the difference was statistically significant $(\mathrm{P}<0.05)$. Combined with the above results, the lung injury of patients undergoing lung cancer resection with propofol was lower than that of sevoflurane, especially at T4. The level of A-aDO2, RI, Qs/Qt and MMP-9 in the serum of the patients of the two groups showed a trend of first increase and then decrease, but the level of A-aDO2, Qs/Qt and MMP-9 in propofol group was significantly lower than that in sevoflurane group. Findings of Tian et al (19) were basically consistent with ours, possibly because inhalation of sevoflurane released inflammatory mediators and made inflammatory cytokines highly expressed, leading to more severe lung injury in patients (20). Other studies have shown that inhalation of anaesthesia may cause reversible pulmonary alveolar fluid and a decrease of lung water clearance by affecting biomembrane, leading to perioperative pulmonary edema and thus affecting oxygen diffusion function (21). Animal experiments have shown that inhalation of anaesthesia can inhibit type II alveolar epithelial cells (AECII) from synthetizing pulmonary surfactant or decrease their activities (22).

MMSE scale is one of the most important evaluation indicators, which has the advantages of simple operation, high efficiency and high reliability (23). Especially, lung cancer resection impairs the cognitive function of patients to a certain extent. Under the influence of surgical resection of lung tissue, lung cancer resection can reduce the ratio of ventilation volume to blood flow to a certain extent, resulting in hypoxemia and impairment of cognitive function of patients (24). In this study, there was no significant difference in MMSE score between sevoflurane and propofol group 1 day before surgery $(\mathrm{P}>0.05)$. The MMSE score in sevoflurane group was significantly lower than that in propofol group 1 and 10 days after surgery, and the difference was statistically significant $(\mathrm{P}<0.05)$. Both sevoflurane and propofol groups had significantly lower MMSE score of 1 and 10 days after surgery than that of day 1 before surgery. Both sevoflurane and propofol groups had significantly higher MMSE score of 10 days after surgery than that of 1 day after surgery, and the difference was statistically significant $(\mathrm{P}<0.05)$. Combined with the above results, it showed that the use of propofol was beneficial to the recovery of cognitive function in patients, which was consistent with the results of Jin et al (25). The reason may be that sevoflurane can make increased permeability of mitochondrial membrane, activity of oxygen free radical, and enzyme concentration of inducing apoptosis, leading to postoperative amnesia in patients (26).

However, there are still some limitations in this study. We hope that in the future, the research can be further deepened, and additional univariate analysis can be performed to compare the relationship between each clinical parameter and the A-aDO2, RI, MMP-9 and MMSE scores, or the multivariate analysis involving each clinical parameter as an independent variable.

In conclusion, propofol has little effect on pulmonary function and can reduce inflammation. Both sevoflurane and propofol have an effect on cognitive function after lung cancer resection. However, propofol can reduce cognitive impairment in patients, and provide theoretical basis for better clinical choice of anaesthesia.

\section{Acknowledgements}

Not applicable.

\section{Funding}

No funding was received.

\section{Availability of data and materials}

The datasets used and/or analyzed during the present study are available from the corresponding author on reasonable request.

\section{Authors' contributions}

GW was responsible for the conception and design of the work. GW and JL collected general data of patients. JG was responsible for the treatment. GW and XZ analyzed observation index, and drafted and revised the manuscript. All authors read and approved the final manuscript.

\section{Ethics approval and consent to participate}

The study was approved by the Ethics Committee of The Second Hospital of Dalian Medical University (Dalian, China). Patients who participated in this research had complete clinical data. The signed informed consents were obtained from the patients or the guardians.

\section{Patient consent for publication}

Not applicable.

\section{Competing interests}

The authors declare that they have no competing interests.

\section{References}

1. Herbst RS, Heymach JV and Lippman SM: Lung cancer. N Engl J Med 359: 1367-1380, 2008.

2. Pope CA III, Burnett RT, Thun MJ, Calle EE, Krewski D, Ito K and Thurston GD: Lung cancer, cardiopulmonary mortality, and long-term exposure to fine particulate air pollution. JAMA 287 : 1132-1141, 2002.

3. Shepherd FA, Rodrigues Pereira J, Ciuleanu T, Tan EH, Hirsh V, Thongprasert S, Campos D, Maoleekoonpiroj S, Smylie M, Martins R, et al; National Cancer Institute of Canada Clinical Trials Group: Erlotinib in previously treated non-small-cell lung cancer. N Engl J Med 353: 123-132, 2005.

4. Engelman JA, Zejnullahu K, Mitsudomi T, Song Y, Hyland C, Park JO, Lindeman N, Gale CM, Zhao X, Christensen J, et al: MET amplification leads to gefitinib resistance in lung cancer by activating ERBB3 signaling. Science 316: 1039-1043, 2007.

5. Bekker A, Korban A and Esochaghi S: Long-term cognitive decline in the elderly is not attributable to surgery/anesthesia. Int J Anesthesiol Res 5: 490-493, 2017.

6. Shi HJ, Xue XH, Wang YL, Zhang WS, Wang ZS and Yu AL: Effects of different anesthesia methods on cognitive dysfunction after hip replacement operation in elder patients. Int J Clin Exp Med 8: 3883-3888, 2015. 
7. Tian HT, Duan XH, Yang YF, Wang Y, Bai QL and Zhang X: Effects of propofol or sevoflurane anesthesia on the perioperative inflammatory response, pulmonary function and cognitive function in patients receiving lung cancer resection. Eur Rev Med Pharmacol Sci 21: 5515-5522, 2017.

8. Hsu AT, Barrett CD, DeBusk GM, Ellson CD, Gautam S, Talmor DS, Gallagher DC and Yaffe MB: Kinetics and role of plasma matrix metalloproteinase-9 expression in acute lung injury and the acute respiratory distress syndrome. Shock 44: 128-136, 2015.

9. Shan JG, Xue S, Xu GX, Wang WJ, Lian F, Liu S, Hu ZL and Huang RT: Effects of acupuncture-drug compound anesthesia on perioperative inflammatory factors in patients undergoing cardiac surgery. Zhongguo Zhenjiu 30: 585-588, 2010. (In Chinese).

10. Luo YX, Huang B and Ying LI: Effects of anesthetics on inflammatory response and lung function of patients undergoing radical esophageal cancer surgery. Zhongguo Yiyuan Ganranxue Zazhi 4: 877-879 (In Chinese).

11. Zhang L, Chen C, Wang L, Cheng G, Wu WW and Li YH: Awakening from anesthesia using propofol or sevoflurane withepidural block in radical surgery for senile gastric cancer. Int J Clin Exp Med 8: 19412-19417, 2015.

12. Zhao X, Jin YW, Li HB, Wang ZG, Feng H and Feng C: Effects of maintaining intravenous infusion of remifentanil or propofol on anesthesia and palinesthesia during anesthesia and analepsia. Genet Mol Res 13: 2865-2872, 2014

13. Jin Y, Zhao X, Li H, Wang Z and Wang D: Effects of sevoflurane and propofol on the inflammatory response and pulmonary function of perioperative patients with one-lung ventilation. Exp Ther Med 6: 781-785, 2013.

14. Hu XL, Tang HH, Zhou ZG, Yin F and Liu WJ: The effect of sevoflurane inhalation anesthesia only and propofol total intravenous anesthesia on perioperative cytokine balance inlung cancer patients. Xi Bao Yu Fen Zi Mian Yi Xue Za Zhi 27:659-661, 2011 (In Chinese)

15. Suemitsu R, Takeo S, Hamatake M, Morokuma A, Suemori Y and Tanaka $\mathrm{H}$ : The results of surgery under general anesthesia in patients with lung cancer. Surg Today 41: 60-66, 2011.

16. Qiu Q, Choi SW, Wong SS, Irwin MG and Cheung CW: Effects of intra-operative maintenance of general anaesthesia with propofol on postoperative pain outcomes - a systematic review and meta-analysis. Anaesthesia 71: 1222-1233, 2016.

17. Sorour K, Vyas PA, Raval DS, Donovan LM and Vyas AA: Successful treatment of severe asthma exacerbation with sevoflurane inhalation in the intensive care unit. J Anesth Crit Care 3: 00092, 2015
18. Stiles BM, Poon A, Giambrone GP, Gaber-Baylis LK, Wu X, Lee PC, Port JL, Paul S, Bhat AU, Zabih R, et al: Incidence and factors associated with hospital readmission after pulmonary lobectomy. Ann Thorac Surg 101: 434-443, 2016.

19. Tian HT, Duan XH, Yang YF, Wang Y, Bai QL and Zhang X: Effects of propofol or sevoflurane anesthesia on the perioperative inflammatory response, pulmonary function and cognitive function in patients receiving lung cancer resection. Eur Rev Med Pharmacol Sci 21: 5515-5522, 2017.

20. Dai AL, Fan LH, Zhang FJ, Yang MJ, Yu J, Wang JK, Fang T, Chen G, Yu LN and Yan M: Effects of sevoflurane preconditioning and postconditioning on rat myocardial stunning in ischemic reperfusion injury. J Zhejiang Univ Sci B 11: 267-274, 2010.

21. Rezaiguia-Delclaux S, Jayr C, Luo DF, Saïdi NE, Meignan M and Duvaldestin P: Halothane and isoflurane decrease alveolar epithelial fluid clearance in rats. Anesthesiology 88: 751-760, 1998.

22. Molliex S, Crestani B, Dureuil B, Bastin J, Rolland C, Aubier M and Desmonts JM: Effects of halothane on surfactant biosynthesis by rat alveolar type II cells in primary culture. Anesthesiology 81 : 668-676, 1994

23. Zarogoulidis P, Darwiche K, Tsakiridis K, Teschler H, Yarmus L, Zarogoulidis K and Freitag L: Learning from the cardiologists and developing eluting stents targeting the MTOR pathway for pulmonary application; a future concept for tracheal stenosis. J Mol Genet Med 7: 65, 2013.

24. Zhai HR, Yang XN, Nie Q, Liao RQ, Dong S, Li W, Jiang BY, Yang JJ, Zhou Q, Tu HY, et al: Different dissecting orders of the pulmonary bronchus and vessels during right upper lobectomy are associated with surgical feasibility and postoperative recovery for lung cancer patients. Chin J Cancer 36: 53, 2017.

25. Jin Y, Zhao X, Li H, Wang Z and Wang D: Effects of sevoflurane and propofol on the inflammatory response and pulmonary function of perioperative patients with one-lung ventilation. Exp Ther Med 6: 781-785, 2013.

26. Liang H, Gu MN, Yang CX, Wang HB, Wen XJ and Zhou QL: Sevoflurane inhibits proliferation, induces apoptosis, and blocks cell cycle progression of lung carcinoma cells. Asian Pac J Cancer Prev 12: 3415-3420, 2011.

This work is licensed under a Creative Commons Attribution-NonCommercial-NoDerivatives 4.0 International (CC BY-NC-ND 4.0) License. 